\title{
The Newsvendor Problem with Different Delivery Time, Resalable Returns, and an Additional Order
}

\author{
Fue Zeng, ${ }^{1}$ Yunjia Chi, ${ }^{1}$ and Jinhui Zheng ${ }^{2}$ \\ ${ }^{1}$ Department of Marketing, Economics and Management School, Wuhan University, Wuhan 430072, China \\ ${ }^{2}$ College of Design, Shenzhen University, Shenzhen 518060, China
}

Correspondence should be addressed to Jinhui Zheng; zhengjinhui.mail@gmail.com

Received 8 August 2014; Revised 7 November 2014; Accepted 17 November 2014

Academic Editor: Tsan-Ming Choi

Copyright (C) 2015 Fue Zeng et al. This is an open access article distributed under the Creative Commons Attribution License, which permits unrestricted use, distribution, and reproduction in any medium, provided the original work is properly cited.

\begin{abstract}
In a $\mathrm{B} 2 \mathrm{C}$ scenario, the retailer is confronted with two kinds of demand. One requires an immediate delivery after placing an order, while the other prefers a delayed shipment due to some personal reasons. Considering demands for different delivery time, we explore a newsvendor model with resalable returns and an additional order to optimize the procurement decision under a stochastic demand distribution. The impact of the proportion of the instant delivery needs and the return rate on the order quantity and the expected profit is illustrated through numerical tests. It is shown that the expected profit decreases as the ratios of immediate delivery needs and returned products increase. Besides, if the sum of the percentage of the instant delivery needs and the return rate is less than 1, the expected profit is always greater than the result if the sum of them is equal to or greater than 1. Management implications are also discussed.
\end{abstract}

\section{Introduction}

Consider the following scenario. Kevin places an order for a free-size navy-blue hoodie online on Monday. In order to get the hoodie as soon as possible, he prefers the immediate delivery. Meanwhile, Jason orders the same hoodie in the same online shop. However, because of a business trip, he asks for his hoodie being sent at least five days later. The next day, Kevin receives his hoodie as scheduled, but it turns out that the color seems so much darker than the one shown on the Internet that he decides to return it instantly. Afterwards, the online shop sends the hoodie that Kevin returned to Jason on Saturday, and Jason is quite satisfied with the product and the timing.

In this scenario, what Kevin and Jason experience is quite prevalent nowadays. With the booming of E-commerce, the number of consumers shopping online shoots up. Comparing to the in-store shopping, however, online consumers are more likely to return products due to a lack of seeing, touching, and trying the commodities, which results in the return rate ranging from $18 \%$ to $74 \%$ [1]. Since consumers return products due to their personal reasons, most of the returns are in good condition and can be resold directly once received by the e-tailer. In this sense, managing the returns becomes an integral part of e-tailers' supply chain management. For instance, when deciding the procurement quantity at the very beginning, the $\mathrm{B} 2 \mathrm{C}$ retailer must take the quantity of resalable returns into account. Additionally, as shown in the previous example, another difference between the online shopping and the in-store shopping is that, in traditional brick-and-mortar shopping, consumers can get the product instantaneously once it is paid. When consumers are shopping on the Internet, they are free to choose an instant delivery or a delayed delivery. In this case, the $\mathrm{B} 2 \mathrm{C}$ retailer is confronted with two kinds of demand, which complicate the process of decision-making about the replenishment quantity. One demand prefers the immediate delivery after placing an order, while the other asks for the delayed shipment. Since the sales in former case may be lost when there is a shortage, the retailer needs to order and decide the procurement quantity at the beginning of the sales period, which is used to meet the instant delivery needs. As to the consumers requiring the delayed delivery, the retailer can satisfy them with the returns arriving before the end of the selling period, 
the remaining stocks of the initial replenishment (if any), and a second order. Based on the abovementioned reasons, both the quantity of resalable returns and the demands for either immediate or delayed delivery have a great influence on inventory management of $\mathrm{B} 2 \mathrm{C}$ retailers. Thus, Internet retailers' flexibility in deciding the order quantity is of vital importance, which aims at maximizing their profit as well as achieving an optimal service level.

Since returns play such an important role in deciding order quantity, much of the existing literature dealing with procurement decisions considers the case with returns that need recovery, remanufacture, or recycle $[2,3]$. They mainly analyze the impact of the quality and quantity of the returned goods and the lead-time to refurbish them on the decisionmaking about the order quantity. Generally, this kind of problem focuses on the traditional business because when shopping at the physical store, consumers can have a better overall idea about the product's size, texture, appearance, and performance before purchasing. Hence, the ratio of returns due to quality problems or the end of service life is much larger than the ratio of returns due to personal preference [4]. Besides, most of the former returns need refurbishing, remanufacturing, or recovery. So, in the background of traditional business, the research usually focuses on returned products with quality problem, which is refurbished or recovered before reselling to the market.

In contrast with consumers shopping at the physical store, online consumers evaluate the commodity through pictures displayed on the website. Therefore, they return products mostly because what they get eventually is different from what they saw on the Internet. The ratio of returns as good as new constitutes a large amount of total returns [5]. When deciding the order quantity, the quantity of the resalable returns should be taken into account. So, another stream of literature modeling procurement decisions has emerged, analyzing the effect of the quantity of resalable returns $[1,5,6]$ and the return policy [7-10] on the order quantity of Internet retailers.

In the context of E-commerce, not only do the returns affect the replenishment decision, but also demands for different delivery time have influence on it. Online consumers can choose between receiving the product as soon as possible and delaying the delivery time, which is the unique feature of online shopping differing from in-store shopping. To the best of our knowledge, few literatures consider the different delivery time. Hence, we extend existing research to the case considering demands for different delivery options as well as the returns.

Previous literature models a procurement decision with returns from the perspectives of either the single period or the multiperiod, depending on the properties of the products in the research. In contrast with the products in the multiperiod model, the goods in a single period model are highly seasonal or more perishable [11]. In the context of e-business, commodities with short period and seasonal characteristics such as apparel and personal electronics account for most of the sales [12], which leads us to formulate the problem based on a single period model (also known as the newsboy or newsvendor model).
Comparing to the classic newsvendor model that only one order is placed before the beginning of the sales period, a recourse case is proposed where an additional replenishment takes place during or at the end of the period [13-15]. Research on the single period problem with a second order points out that an additional order chance can effectively improve the accuracy of demand forecasting and increase revenue. However, existing research dealing with a second procurement ignores the effect of returns. Besides, research considers returns without taking an additional order into account. Thus, we extend the classic newsvendor model to the one considering both resalable returns and an additional order simultaneously.

For brevity, the following novel contributions differentiate our model from the abovementioned literature. First of all, in a $\mathrm{B} 2 \mathrm{C}$ scenario, the delivery time uncertainty is considered. We distinguish the demand asking for immediate delivery from the demand requiring delayed shipment and analyze their impact on the procurement decisions and the expected profit of the $\mathrm{B} 2 \mathrm{C}$ retailer. Additionally, we extend the newsboy problem to the model considering both resalable returns and a second order simultaneously. Considering demands for different delivery time, resalable returns, and an additional replenishment, we formulate the problem based on the newsvendor model to analyze the order quantity that not only maximizes Internet retailers' profit but also optimizes their service level.

The remainder of the paper is organized as follows. Section 2 reviews the relevant literature and points out the characteristics of the paper. Section 3 delineates the problem in detail. Section 4 introduces the notation and formulates the expected profit function of the $\mathrm{B} 2 \mathrm{C}$ retailer. In Section 5 , a brief numerical illustration is presented, from which some observations and management implications are deduced. Last but not least, Section 6 summarizes the findings of the paper and shows some extensions.

\section{Literature Review}

Research concentrating on procurement decisions has been increasing rapidly. There are three streams of research related to our problem. The first stream focuses on used returns that need to be refurbished before reselling. Providing the demand is known and returns are stochastic; Ferrer [16] presents a remanufacturing procedure with only one collection site. Robotis et al. [17] extend Ferrer's system to two collection sites storing two distinct returned products, respectively. Based on the system proposed by Robotis et al., Webster and Weng [11] examine a system with two collection sites and one refurbishing site. Not only do they derive the optimal production and procurement quantities maximizing the profit of the entire supply chain, but also they figure out under what condition it is better to use only one of the collection sites. Additionally, since timely quality information is of vital importance, Teng et al. [10] demonstrate a quality classification scheme for the automotive industry. In a similar vein, Ferguson et al. [4] further explore the value of classification according to different quality levels. In order to timely evaluate the quality of returns, Panagiotidou et al. [2] study 
the sampling inspection in a remanufacturing system, which improves the procurement decision. The aforesaid literature mainly concentrates on returns from offline consumers. Because they can have a better understanding of products before purchasing, offline consumers usually return products because of quality problems. So, the quality and quantity of returns and the lead-time to remanufacture them are considered. In contrast, we concentrate on the intact returns, the quality of which is as good as the new. There is no need to recover the returned products and they can be resold after a quick quality check.

Returns requiring refurbishing or recovery take the lion's share of total returns in the background of traditional business. However, since online consumers make purchase decisions mostly based on picture on the Internet, their likelihood to return intact products is high due to the fact that the item they receive is usually far from what they expected. In most cases, the items they return have no difference from brand new commodities. So a second group of literature deals with this kind of returned products, which can be resold instantly. According to the values of the cost coefficients, Vlachos and Dekker [5] first study the optimal replenishment strategies with uncontrollable return flows. Under the condition of various return options, they derive different optimal order quantities. Mostard and Teunter [1] relax two hypotheses in the research of Vlachos and Dekker, which assume that commodities can be returned only once and the proportion of the returns is fixed. In the model of Mostard and Teunter, products can be returned more than once. Furthermore, in consideration of the variability in the percentage of returns, they figure out a closed-form equation determining the optimal order quantity. Last but not least, using real data from a mail order enterprise, they compare the procurement quantity deduced from their model to those presented by Vlachos and Dekker and to the original order quantity of the company. Most of the earlier research uses historical data to forecast the mean and standard deviation of demand. In practice, however, sales data of highly seasonal products is difficult to obtain. Mostard et al. [6] extend the newsvendor problem to a distribution-free one with resalable returns. Even though the existing literature analyzes the impact of resalable returns on procurement decisions, few of them take an additional order into consideration at the same time, which can significantly improve the accuracy of demand forecast and increase profit.

Comparing to the classic newsvendor model, where the order can only be placed once before the sales period, Gallego and Moon [13] analyze a recourse case based on the distribution-free newsvendor problem. The unsatisfied demand is assumed to be deterministic and can be met by an additional replenishment at the end of the season. Kodama [18] discusses a sophisticated situation with returns to manufacturer in the case of surplus and a second order in the case of stock-out. Two cases are considered. One is the demand that occurs once only at a particular point of the period. The other is the demand that follows a general demand pattern. Similarly, Khouja [14] extends the model of Gallego and Moon to the case that a ratio of the unmet demand is lost immediately and the remainder is satisfied by an emergency order. In contrast, H. S. Lau and A. H. L. Lau [15] introduce the additional order quantity as a second decision variable, which is determined during the midseason compared to the first order quantity determined at the start of the sales period. The coordination between these two decision variables is of vital importance. Previous research considering an additional order ignores the effect of returns. Also, as mentioned, research dealing with returns does not analyze the influence of a second order.

So far, few literatures consider both resalable returns and a second order as we do. Besides, most of the abovementioned research explores the problem in the setting of offline business and refers to the same method in the context of e-business. But consumers are free to choose either an instant delivery or a delayed delivery while shopping online, which differentiates the e-shopping from the in-store shopping. The B2C retailer should take the impact of different delivery time on inventory into consideration when deciding the replenishment quantity at the very beginning. Therefore, based on a newsvendor model, we consider demands for different delivery options, returns, and a second order simultaneously and formulate and optimize the expected profit of the $\mathrm{B} 2 \mathrm{C}$ retailer.

\section{Problem Description}

In the setting of E-commerce, the demand $x$ for a single product is stochastic, which follows a distribution function $F(x)$ and a probability density function $f(x)$. Since the delivery time can be customized to the needs of consumers, demand is classified into two types by the different delivery time that consumers require. Consumers preferring the immediate delivery after placing an order account for $\alpha$ percent (according to historical data, $\alpha$ is a constant) of the total demand, while the proportion of consumers asking for a delayed delivery because of some personal reasons is $(1-\alpha)$. Before the sales period, the vendor needs to estimate the demand asking for instant delivery and to decide the initial order quantity $Q_{1}$, the only decision variable in the model. The retailer purchases at the price $c_{p}$ per unit ordered and sells at the price $p$ per unit sold. All the commodities replenished before the selling season are used to meet the instant delivery needs. Due to forecast errors, this kind of demand is lost at the $\operatorname{cost} c_{s}$ per shortage once there is a stock-out. Otherwise, the remaining stocks are used to satisfy the demand, preferring delayed delivery. Meanwhile, returns arriving before the end of the selling season are assumed to be of the same quality as new products and resold to meet the delayed delivery needs at the same price. Consumers receive a full refund if products are returned. Since the number of returned products is uncontrollable, we assume that the returns comprise $\beta$ percent of total sales. The vendor pays at the unit cost $c_{m}$ to collect, inspect, repack, and restock the returned products. Compared to the classic newsboy model, if the demand requiring delayed delivery is higher than the remaining stocks of the first procurement (if any) and the returned products, according to the unmet needs, an additional order is allowed in our model. Of course, the second order at the end leads to higher purchase cost $\widetilde{c_{p}}$. At the end of the season, unsold products are disposed at the unit $\operatorname{cost} c_{d}$ without salvage value. 


\section{Notation and Models}

Notation

$x$ : Demand

$Q_{0}:$ First order quantity

$Q_{1}$ : Second order quantity

$\alpha$ : Proportion of demand requiring instant delivery $(1<\alpha<0)$

$\beta$ : Proportion of returns $(1<\beta<0)$

$p$ : Unit selling price

$c_{p}$ : First order purchase cost per product

$\widetilde{c_{p}}:$ Second order purchase cost per product

$c_{s}$ : Penalty cost per shortage

$c_{d}$ : Disposal cost per product

$c_{m}$ : Return management cost per returned product

$\pi$ : Profit

$Q_{0}{ }^{*}:$ Optimal order quantity

$E \pi\left(Q_{0}\right)$ : Expected profit for the order quantity $Q_{0}$.

The problem described in the former part has only one decision variable: the first order quantity $Q_{0} . Q_{1}$ is placed at the end of the season after observing the unsatisfied demand. Formulating the expected profit for the replenishment quantity $Q_{0}$, we derive the optimal order quantity $Q_{0}{ }^{*}$. We begin to formulate and optimize the model from the situation without returns, based on which the model considering returns is formulated and optimized.

\subsection{Model without Returns}

Case $A\left(\alpha x \geq Q_{0}, Q_{1}=(1-\alpha) x\right)$. The profit of the $\mathrm{B} 2 \mathrm{C}$ vendor when the first order quantity is $Q_{0}$ and the demand is $x$ is

$\pi\left(Q_{0}, x\right)=p Q_{0}+p(1-\alpha) x-c_{p} Q_{0}-\widetilde{c_{p}} Q_{1}-c_{s}\left(\alpha x-Q_{0}\right)$.

Case $B\left(\alpha x<Q_{0}, Q_{1}=\max \left\{(1-\alpha) x-\left(Q_{0}-\alpha x\right), 0\right\}\right)$. The profit of the B2C vendor when the first order quantity is $Q_{0}$ and the demand is $x$ is

$$
\begin{aligned}
\pi\left(Q_{0}, x\right)= & p \alpha x+p(1-\alpha) x-c_{p} Q_{0}-\widetilde{c_{p}} Q_{1} \\
& -c_{d} \max \left\{\left(Q_{0}-\alpha x\right)-(1-\alpha) x, 0\right\} .
\end{aligned}
$$

Let

$$
\begin{gathered}
H\left(Q_{0}, x\right)=p \min \left\{\alpha x, Q_{0}\right\}+p(1-\alpha) x-c_{p} Q_{0}, \\
G_{1}\left(Q_{0}, x\right)=\widetilde{c_{p}} Q_{1}+c_{s}\left(\alpha x-Q_{0}\right), \\
G_{2}\left(Q_{0}, x\right)=\widetilde{c_{p}} Q_{1}+c_{d} \max \left\{\left(Q_{0}-\alpha x\right)-(1-\alpha) x\right\} .
\end{gathered}
$$

Combining (3), (4), and (5) gives

$$
\pi\left(Q_{0}, x\right)= \begin{cases}H\left(Q_{0}, x\right)-G_{1}\left(Q_{0}, x\right) & x \geq \frac{Q_{0}}{\alpha} \\ H\left(Q_{0}, x\right)-G_{2}\left(Q_{0}, x\right) & \text { otherwise }\end{cases}
$$

The expected profit of the $\mathrm{B} 2 \mathrm{C}$ retailer is

$$
\begin{aligned}
E \pi\left(Q_{0}, x\right)= & \int_{0}^{\infty} H\left(Q_{0}, x\right) f(x) d x \\
& -\int_{0}^{Q_{0} / \alpha} G_{2}\left(Q_{0}, x\right) f(x) d x \\
& -\int_{Q_{0} / \alpha}^{\infty} G_{1}\left(Q_{0}, x\right) f(x) d x .
\end{aligned}
$$

Taking the derivative of (3), (4), and (5),

$$
\begin{aligned}
& \frac{d}{d Q_{0}} \int_{0}^{\infty} H\left(Q_{0}, x\right) f(x) d x \\
& =\int_{0}^{Q_{0} / \alpha} \frac{d}{d Q_{0}} p\left(\alpha x-Q_{0}\right) f(x) d x+\left(p-c_{p}\right) \\
& =-p F\left(\frac{Q_{0}}{\alpha}\right)+\left(p-c_{p}\right) \text {, } \\
& \frac{d}{d Q_{0}} \int_{Q_{0} / \alpha}^{\infty} G_{1}\left(Q_{0}, x\right) f(x) d x \\
& =\int_{Q_{0} / \alpha}^{\infty} \frac{d}{d Q_{0}} c_{s}\left(\alpha x-Q_{0}\right) f(x) d x \\
& -\widetilde{c_{p}}(1-\alpha) \frac{Q_{0}}{\alpha} f\left(\frac{Q_{0}}{\alpha}\right) \frac{1}{\alpha} \\
& =-c_{s}\left[1-F\left(\frac{Q_{0}}{\alpha}\right)\right]-\widetilde{c_{p}}(1-\alpha) \frac{Q_{0}}{\alpha} f\left(\frac{Q_{0}}{\alpha}\right) \frac{1}{\alpha}, \\
& \frac{d}{d Q_{0}} \int_{0}^{Q_{0} / \alpha} G_{2}\left(Q_{0}, x\right) f(x) d x \\
& =\frac{d}{d Q_{0}} \int_{0}^{Q_{0} / \alpha}\left[\widetilde{c_{p}}\left(x-Q_{0}\right)^{+}+c_{d}\left(Q_{0}-x\right)^{+}\right] f(x) d x \\
& =\widetilde{c_{p}}\left(\frac{Q_{0}}{\alpha}-Q_{0}\right) f\left(\frac{Q_{0}}{\alpha}\right) \frac{1}{\alpha} \\
& +\int_{0}^{Q_{0}} \frac{d}{d Q_{0}} c_{d}\left(Q_{0}-x\right) f(x) d x \\
& +\int_{Q_{0}}^{Q_{0} / \alpha} \frac{d}{d Q_{0}} \widetilde{c_{p}}\left(x-Q_{0}\right) f(x) d x \\
& =\widetilde{c_{p}}\left(\frac{Q_{0}}{\alpha}-Q_{0}\right) f\left(\frac{Q_{0}}{\alpha}\right) \frac{1}{\alpha}+c_{d} F\left(Q_{0}\right) \\
& -\widetilde{c_{p}}\left[F\left(\frac{Q_{0}}{\alpha}\right)-F\left(Q_{0}\right)\right] \text {. }
\end{aligned}
$$


Combining (8), (9), and (10) gives

$$
\begin{aligned}
\frac{d}{d Q_{0}} & E \pi\left(Q_{0}, x\right) \\
= & -p F\left(\frac{Q_{0}}{\alpha}\right)+\left(p-c_{p}\right)+c_{s}\left[1-F\left(\frac{Q_{0}}{\alpha}\right)\right] \\
& -c_{d} F\left(Q_{0}\right)+\widetilde{c_{p}}\left[F\left(\frac{Q_{0}}{\alpha}\right)-F\left(Q_{0}\right)\right] \\
= & \left(p+c_{s}-c_{p}\right)-\left(p+c_{s}-\widetilde{c_{p}}\right) F\left(\frac{Q_{0}}{\alpha}\right) \\
& -\left(c_{d}+\widetilde{c_{p}}\right) F\left(Q_{0}\right) .
\end{aligned}
$$

So $\left(d^{2} / d^{2} Q_{0}\right) E \pi\left(Q_{0}, x\right)=-\left(p+c_{s}-\widetilde{c_{p}}\right) f\left(Q_{0} / \alpha\right)(1 / \alpha)-\left(c_{d}+\right.$ $\left.\widetilde{c_{p}}\right) f\left(Q_{0}\right)$.

Because $\left(d^{2} / d^{2} Q_{0}\right) E \pi\left(Q_{0}, x\right)<0, E \pi\left(Q_{0}, x\right)$ is strictly concave.

Let $\left(d / d Q_{0}\right) E \pi\left(Q_{0}, x\right)=0$.

Denote $r=\left(p+c_{s}-\widetilde{c_{p}}\right) /\left(p+c_{s}+c_{d}\right)$ and $1-r=\left(c_{d}+\right.$ $\left.\widetilde{c_{p}}\right) /\left(p+c_{s}+c_{d}\right)$.

Then, $\left(p+c_{s}-c_{p}\right)-\left(p+c_{s}+c_{d}\right)\left[r F\left(Q_{0} / \alpha\right)+(1-r) F\left(Q_{0}\right)\right]=0$.

As $F(x)$ is a cumulative distribution function (of course nondecreasing function), we can derive

$$
\begin{gathered}
\left(p+c_{s}-c_{p}\right)-\left(p+c_{s}+c_{d}\right) \\
\times\left[r F\left(\frac{Q_{0}}{\alpha}\right)+(1-r) F\left(\frac{Q_{0}}{\alpha}\right)\right] \leq 0 \\
\left(p+c_{s}-c_{p}\right)-\left(p+c_{s}+c_{d}\right)\left[r F\left(Q_{0}\right)+(1-r) F\left(Q_{0}\right)\right] \geq 0 .
\end{gathered}
$$

The optimal order quantity $Q_{0}{ }^{*}$ belongs to a closed interval

$$
Q_{0}{ }^{*} \in\left[\alpha F^{-1}\left(\frac{p+c_{s}-c_{p}}{p+c_{s}+c_{d}}\right), F^{-1}\left(\frac{p+c_{s}-c_{p}}{p+c_{s}+c_{d}}\right)\right] .
$$

\subsection{Model with Returns}

Case $A\left(\alpha x \geq Q_{0}, Q_{1}=\max \left\{(1-\alpha) x-\beta\left[Q_{0}+(1-\alpha) x\right], 0\right\}\right)$. The profit of the $\mathrm{B} 2 \mathrm{C}$ vendor when the first order quantity is $Q_{0}$ and the demand is $x$ is

$$
\begin{aligned}
\pi\left(Q_{0}, x\right)= & p Q_{0}+p(1-\alpha) x-\left(p+c_{m}\right) \beta\left[Q_{0}+(1-\alpha) x\right] \\
& -c_{s}\left(\alpha x-Q_{0}\right)-c_{p} Q_{0}-\widetilde{c_{p}} Q_{1} \\
& -c_{d} \max \left\{\beta\left[Q_{0}+(1-\alpha) x\right]-(1-\alpha) x, 0\right\} .
\end{aligned}
$$

Case $B\left(\alpha x<Q_{0}, Q_{1}=\max \left\{(1-\alpha) x-\beta x-\left(Q_{0}-\alpha x\right), 0\right\}\right)$. The profit of the $\mathrm{B} 2 \mathrm{C}$ vendor when the first order quantity is $Q_{0}$ and the demand is $x$ is

$$
\begin{aligned}
\pi\left(Q_{0}, x\right)= & p \alpha x+p(1-\alpha) x-\left(p+c_{m}\right) \beta x-c_{p} Q_{0}-\widetilde{c_{p}} Q_{1} \\
& -c_{d} \max \left\{\beta x+\left(Q_{0}-\alpha x\right)-(1-\alpha) x, 0\right\} .
\end{aligned}
$$

Let

$$
\begin{aligned}
& H\left(Q_{0}, x\right)= p \min \left\{\alpha x-Q_{0}, 0\right\}+p(1-\alpha) x-\left(p+c_{m}\right) \beta x \\
&-c_{s} \max \left\{\alpha x-Q_{0}, 0\right\}+\left(p-c_{p}\right) Q_{0}, \\
& G_{1}\left(Q_{0}, x\right)= \widetilde{c_{p}} Q_{1}-\left(p+c_{m}\right)\left(Q_{0}-\alpha x\right) \beta \\
&+c_{d} \max \left\{\beta\left[Q_{0}+(1-\alpha) x\right]-(1-\alpha) x, 0\right\}, \\
& G_{2}\left(Q_{0}, x\right)=\widetilde{c_{p}} Q_{1}+c_{d} \max \left\{\beta x+\left(Q_{0}-\alpha x\right)-(1-\alpha) x, 0\right\} .
\end{aligned}
$$

Combining (16), (17), and (18) gives

$$
\pi\left(Q_{0}, x\right)= \begin{cases}H\left(Q_{0}, x\right)-G_{1}\left(Q_{0}, x\right) & x \geq \frac{Q_{0}}{\alpha} \\ H\left(Q_{0}, x\right)-G_{2}\left(Q_{0}, x\right) & \text { otherwise }\end{cases}
$$

The expected profit of the $\mathrm{B} 2 \mathrm{C}$ retailer is

$$
\begin{aligned}
E \pi\left(Q_{0}, x\right)= & \int_{0}^{\infty} H\left(Q_{0}, x\right) f(x) d x \\
& -\int_{0}^{Q_{0} / \alpha} G_{2}\left(Q_{0}, x\right) f(x) d x \\
& -\int_{Q_{0} / \alpha}^{\infty} G_{1}\left(Q_{0}, x\right) f(x) d x .
\end{aligned}
$$

Taking the derivative of (16), (17), and (18),

$$
\begin{aligned}
\frac{d}{d Q_{0}} & \int_{0}^{\infty} H\left(Q_{0}, x\right) f(x) d x \\
= & \int_{0}^{Q_{0} / \alpha} \frac{d}{d Q_{0}} p\left(\alpha x-Q_{0}\right) f(x) d x \\
& +\int_{Q_{0} / \alpha}^{\infty} \frac{d}{d Q_{0}}\left[-c_{s}\left(\alpha x-Q_{0}\right)\right]+\left(p-c_{p}\right) \\
= & \int_{0}^{Q_{0} / \alpha}-p f(x) d x+\int_{Q_{0} / \alpha}^{\infty} c_{s} f(x) d x+\left(p-c_{p}\right) \\
= & -p F\left(\frac{Q_{0}}{\alpha}\right)+c_{s}\left[1-F\left(\frac{Q_{0}}{\alpha}\right)\right]+\left(p-c_{p}\right) \\
= & \left(p+c_{s}-c_{p}\right)-\left(p+c_{s}\right) F\left(\frac{Q_{0}}{\alpha}\right),
\end{aligned}
$$


6

Mathematical Problems in Engineering

$$
\begin{aligned}
& (*)=\frac{d}{d Q_{0}} \int_{Q_{0} / \alpha}^{\infty} G_{1}\left(Q_{0}, x\right) f(x) d x \\
& =\frac{d}{d Q_{0}} \int_{Q_{0} / \alpha}^{\infty}\left\{\widetilde{c_{p}}\left[(1-\alpha) x-\beta\left(Q_{0}+(1-\alpha) x\right)\right]^{+}\right. \\
& +c_{d}\left[\beta\left(Q_{0}+(1-\alpha) x\right)-(1-\alpha) x\right]^{+} \\
& \left.-\beta\left(p+c_{m}\right)\left(Q_{0}-\alpha x\right)\right\} f(x) d x \\
& =g\left(Q_{0}\right)+\int_{Q_{0} / \alpha}^{\infty} \frac{d}{d Q_{0}} \\
& \times\left\{\widetilde{c_{p}}\left[(1-\alpha) x-\beta\left(Q_{0}+(1-\alpha) x\right)\right]^{+}\right. \\
& +c_{d}\left[\beta\left(Q_{0}+(1-\alpha) x\right)-(1-\alpha) x\right]^{+} \\
& \left.-\beta\left(p+c_{m}\right)\left(Q_{0}-\alpha x\right)\right\} f(x) d x \\
& =g\left(Q_{0}\right)-\beta\left(p+c_{m}\right)\left[1-F\left(\frac{Q_{0}}{\alpha}\right)\right] \\
& +\int_{Q_{0} / \alpha}^{\infty} \frac{d}{d Q_{0}}\left\{\widetilde{c_{p}}\left[(1-\alpha)(1-\beta) x-\beta Q_{0}\right]^{+}\right. \\
& \left.+c_{d}\left[\beta Q_{0}-(1-\alpha)(1-\beta) x\right]^{+}\right\} f(x) d x,
\end{aligned}
$$

where $g\left(Q_{0}\right)=-(1 / \alpha) f\left(Q_{0} / \alpha\right)\left\{\widetilde{c_{p}}\left[(1-\alpha)\left(Q_{0} / \alpha\right)-\beta\left(Q_{0} /\right.\right.\right.$ $\left.\alpha)]^{+}+c_{d}\left[\beta\left(Q_{0} / \alpha\right)-(1-\alpha)\left(Q_{0} / \alpha\right)\right]^{+}\right\}$and

$$
\begin{aligned}
(* *) & =\frac{d}{d Q_{0}} \int_{Q_{0} / \alpha}^{\infty} G_{2}\left(Q_{0}, x\right) f(x) d x \\
& =-g\left(Q_{0}\right)+\int_{0}^{Q_{0} / \alpha} G_{2}\left(Q_{0}, x\right) f(x) d x .
\end{aligned}
$$

(i) Consider $\alpha<1-\beta$ and then $\beta /(1-\beta)(1-\alpha)<1 / \alpha$ :

$$
\begin{aligned}
(*)= & g\left(Q_{0}\right)-\beta\left(p+c_{m}\right)\left[1-F\left(\frac{Q_{0}}{\alpha}\right)\right] \\
& +\int_{Q_{0} / \alpha}^{\infty} \frac{d}{d Q_{0}} \widetilde{c_{p}}\left[(1-\alpha)(1-\beta) x-\beta Q_{0}\right] f(x) d x \\
= & g\left(Q_{0}\right)-\beta\left(p+c_{m}\right)\left[1-F\left(\frac{Q_{0}}{\alpha}\right)\right] \\
& -\beta \widetilde{c_{p}}\left[1-F\left(\frac{Q_{0}}{\alpha}\right)\right] \\
= & g\left(Q_{0}\right)-\beta\left(p+c_{m}+\widetilde{c_{p}}\right)\left[1-F\left(\frac{Q_{0}}{\alpha}\right)\right],
\end{aligned}
$$

$$
\begin{aligned}
(* *)= & -g\left(Q_{0}\right)+\int_{Q_{0} /(1-\beta)}^{Q_{0} / \alpha} \frac{d}{d Q_{0}} \widetilde{c_{p}}\left[(1-\beta) x-Q_{0}\right] f(x) d x \\
& +\int_{0}^{Q_{0} /(1-\beta)} \frac{d}{d Q_{0}} c_{d}\left[Q_{0}-(1-\beta) x\right] f(x) d x \\
= & -g\left(Q_{0}\right)-\widetilde{c_{p}}\left[F\left(\frac{Q_{0}}{\alpha}\right)-F\left(\frac{Q_{0}}{1-\beta}\right)\right]+c_{d} F\left(\frac{Q_{0}}{1-\beta}\right) \\
= & -g\left(Q_{0}\right)-\widetilde{c_{p}} F\left(\frac{Q_{0}}{\alpha}\right)+\left(\widetilde{c_{p}}+c_{d}\right) F\left(\frac{Q_{0}}{1-\beta}\right) .
\end{aligned}
$$

Combining (21), (24), and (25) gives

$$
\begin{aligned}
\frac{d}{d Q_{0}} E \pi\left(Q_{0}, x\right) \\
=\frac{d}{d Q_{0}} \int_{0}^{\infty} H\left(Q_{0}, x\right) f(x) d x-(*)-(* *) \\
=\left(p+c_{s}-c_{p}\right)-\left(p+c_{s}\right) F\left(\frac{Q_{0}}{\alpha}\right)+\beta\left(p+c_{m}+\widetilde{c_{p}}\right) \\
\quad-\left[\beta\left(p+c_{m}+\widetilde{c_{p}}\right)-\widetilde{c_{p}}\right] F\left(\frac{Q_{0}}{1-\beta}\right) \\
=\left(p+c_{s}-c_{p}\right)+\beta\left(p+c_{m}+\widetilde{c_{p}}\right) \\
\quad-\left[p+c_{s}-\widetilde{c_{p}}+\beta\left(p+c_{m}+\widetilde{c_{p}}\right)\right] F\left(\frac{Q_{0}}{\alpha}\right) \\
\quad-\left(\widetilde{c_{p}}+c_{d}\right) F\left(\frac{Q_{0}}{1-\beta}\right) .
\end{aligned}
$$

Let $\left(d / d Q_{0}\right) E \pi\left(Q_{0}, x\right)=0$.

Denote $r=\left(p+c_{s}-\widetilde{c_{p}}+\beta\left(p+c_{m}+\widetilde{c_{p}}\right)\right) /\left(p+c_{s}+c_{d}+\beta(p+\right.$ $\left.\left.c_{m}+\widetilde{c_{p}}\right)\right)$ and $1-r=\left(\widetilde{c_{p}}+c_{d}\right) /\left(p+c_{s}+c_{d}+\beta\left(p+c_{m}+\widetilde{c_{p}}\right)\right)$.

Then, $\left(p+c_{s}-c_{p}\right)+\beta\left(p+c_{m}+\widetilde{c_{p}}\right)-\left[p+c_{s}+c_{d}+\beta(p+\right.$ $\left.\left.c_{m}+\widetilde{c_{p}}\right)\right]\left[r F\left(Q_{0} / \alpha\right)+(1-r) F\left(Q_{0} /(1-\beta)\right)\right]=0$.

As $F(x)$ is a cumulative distribution function (of course nondecreasing function), we can derive

$$
\begin{aligned}
& \left(p+c_{s}-c_{p}\right)+\beta\left(p+c_{m}+\widetilde{c_{p}}\right) \\
& -\left[p+c_{s}+c_{d}+\beta\left(p+c_{m}+\widetilde{c_{p}}\right)\right] \\
& \quad \times\left[r F\left(\frac{Q_{0}}{\alpha}\right)+(1-r) F\left(\frac{Q_{0}}{\alpha}\right)\right] \leq 0, \\
& \left(p+c_{s}-c_{p}\right)+\beta\left(p+c_{m}+\widetilde{c_{p}}\right) \\
& \quad-\left[p+c_{s}+c_{d}+\beta\left(p+c_{m}+\widetilde{c_{p}}\right)\right] \\
& \quad \times\left[r F\left(\frac{Q_{0}}{1-\beta}\right)+(1-r) F\left(\frac{Q_{0}}{1-\beta}\right)\right] \geq 0 .
\end{aligned}
$$


The optimal order quantity $Q_{0}{ }^{*}$ belongs to a closed interval

$$
\begin{aligned}
Q_{0}{ }^{*} \in\left[\alpha F^{-1}\left(\frac{p+c_{s}-c_{p}+\beta\left(p+c_{m}+\widetilde{c_{p}}\right)}{p+c_{s}+c_{d}+\beta\left(p+c_{m}+\widetilde{c_{p}}\right)}\right),\right. \\
\left.\quad(1-\beta) F^{-1}\left(\frac{p+c_{s}-c_{p}+\beta\left(p+c_{m}+\widetilde{c_{p}}\right)}{p+c_{s}+c_{d}+\beta\left(p+c_{m}+\widetilde{c_{p}}\right)}\right)\right] .
\end{aligned}
$$

(ii) Consider $\alpha \geq 1-\beta$ and then $\beta /(1-\beta)(1-\alpha) \geq 1 / \alpha$ :

$$
\begin{aligned}
(*)= & g\left(Q_{0}\right)-\beta\left(p+c_{m}\right)\left[1-F\left(\frac{Q_{0}}{\alpha}\right)\right] \\
& +\int_{\beta Q_{0} /(1-\beta)(1-\alpha)}^{\infty} \frac{d}{d Q_{0}} \widetilde{c_{p}}\left[(1-\alpha)(1-\beta) x-\beta Q_{0}\right] \\
& \times f(x) d x \\
& +\int_{Q_{0} / \alpha}^{\beta Q_{0} /(1-\beta)(1-\alpha)} \frac{d}{d Q_{0}} c_{d}\left[\beta Q_{0}-(1-\alpha)(1-\beta) x\right] \\
= & g\left(Q_{0}\right)-\beta\left(p+c_{m}\right)\left[1-F\left(\frac{Q_{0}}{\alpha}\right)\right] \\
& -\beta \widetilde{c_{p}}\left[1-F\left(\frac{\beta Q_{0}}{(1-\beta)(1-\alpha)}\right)\right] \\
& +\beta c_{d} F\left(\frac{\beta Q_{0}}{(1-\beta)(1-\alpha)}\right)-F\left(\frac{Q_{0}}{\alpha}\right) \\
= & g\left(Q_{0}\right)-\beta\left(p+c_{m}+\widetilde{c_{p}}\right)+\beta\left(p+c_{m}-c_{d}\right) F\left(\frac{Q_{0}}{\alpha}\right) \\
& +\beta\left(\widetilde{c_{p}}+c_{d}\right) F\left(\frac{\beta Q_{0}}{(1-\beta)(1-\alpha)}\right),
\end{aligned}
$$$$
(* *)=-g\left(Q_{0}\right)+\int_{0}^{Q_{0} / \alpha} \frac{d}{d Q_{0}} c_{d}\left[Q_{0}-(1-\beta) x\right] f(x) d x
$$$$
=-g\left(Q_{0}\right)+\int_{0}^{Q_{0} / \alpha} c_{d} f(x) d x=-g\left(Q_{0}\right)+c_{d} F\left(\frac{Q_{0}}{\alpha}\right) .
$$

$$
\begin{aligned}
= & \left(p+c_{s}-c_{p}\right)-\left(p+c_{s}\right) F\left(\frac{Q_{0}}{\alpha}\right)+\beta\left(p+c_{m}-\widetilde{c_{p}}\right) \\
& -\beta\left(p+c_{m}-c_{d}\right) F\left(\frac{Q_{0}}{\alpha}\right) \\
& -\beta\left(\widetilde{c_{p}}+c_{d}\right) F\left(\frac{\beta Q_{0}}{(1-\beta)(1-\alpha)}\right)-c_{d} F\left(\frac{Q_{0}}{\alpha}\right) \\
= & \left(p+c_{s}-c_{p}\right)+\beta\left(p+c_{m}-\widetilde{c_{p}}\right) \\
& -\left[p+c_{s}+c_{d}+\beta\left(p+c_{m}-c_{d}\right)\right] F\left(\frac{Q_{0}}{\alpha}\right) \\
& -\beta\left(\widetilde{c_{p}}+c_{d}\right) F\left(\frac{\beta Q_{0}}{(1-\beta)(1-\alpha)}\right) .
\end{aligned}
$$

Let $\left(d / d Q_{0}\right) E \pi\left(Q_{0}, x\right)=0$.

Denote $r=\left(p+c_{s}+c_{d}+\beta\left(p+c_{m}-c_{d}\right)\right) /\left(p+c_{s}+c_{d}+\beta(p+\right.$ $\left.\left.c_{m}+\widetilde{c_{p}}\right)\right)$ and $1-r=\beta\left(\widetilde{c_{p}}+c_{d}\right) /\left(p+c_{s}+c_{d}+\beta\left(p+c_{m}+\widetilde{c_{p}}\right)\right)$.

Then, $\left(p+c_{s}-c_{p}\right)+\beta\left(p+c_{m}-\widetilde{c_{p}}\right)-\left[p+c_{s}+c_{d}+\beta\left(p+c_{m}\right.\right.$ $\left.\left.+\widetilde{c_{p}}\right)\right]\left[r F\left(Q_{0} / \alpha\right)+(1-r) F\left(\beta Q_{0} /(1-\beta)(1-\alpha)\right)\right]=0$.

As $F(x)$ is a cumulative distribution function (of course nondecreasing function), we can derive

$$
\begin{aligned}
& \left(p+c_{s}-c_{p}\right)+\beta\left(p+c_{m}-\widetilde{c_{p}}\right) \\
& \quad-\left[p+c_{s}+c_{d}+\beta\left(p+c_{m}+\widetilde{c_{p}}\right)\right] \\
& \quad \times\left[r F\left(\frac{Q_{0}}{\alpha}\right)+(1-r) F\left(\frac{Q_{0}}{\alpha}\right)\right] \geq 0, \\
& \left(p+c_{s}-c_{p}\right)+\beta\left(p+c_{m}-\widetilde{c_{p}}\right) \\
& \quad-\left[p+c_{s}+c_{d}+\beta\left(p+c_{m}+\widetilde{c_{p}}\right)\right] \\
& \quad \times\left[r F\left(\frac{\beta Q_{0}}{(1-\beta)(1-\alpha)}\right)+(1-r) F\left(\frac{\beta Q_{0}}{(1-\beta)(1-\alpha)}\right)\right] \\
& \leq 0 .
\end{aligned}
$$

The optimal order quantity $Q_{0}{ }^{*}$ belongs to a closed interval

$$
\begin{aligned}
& Q_{0}{ }^{*} \in[ \frac{(1-\beta)(1-\alpha)}{\beta} F^{-1}\left(\frac{p+c_{s}-c_{p}+\beta\left(p+c_{m}-\widetilde{c_{p}}\right)}{p+c_{s}+c_{d}+\beta\left(p+c_{m}+\widetilde{c_{p}}\right)}\right), \\
&\left.\alpha F^{-1}\left(\frac{p+c_{s}-c_{p}+\beta\left(p+c_{m}-\widetilde{c_{p}}\right)}{p+c_{s}+c_{d}+\beta\left(p+c_{m}+\widetilde{c_{p}}\right)}\right)\right] .
\end{aligned}
$$

Combining (21), (29), and (30) gives

$$
\begin{aligned}
& \frac{d}{d Q_{0}} E \pi\left(Q_{0}, x\right) \\
& \quad=\frac{d}{d Q_{0}} \int_{0}^{\infty} H\left(Q_{0}, x\right) f(x) d x-(*)-(* *)
\end{aligned}
$$

\section{Numerical Test}

The purpose of the numerical illustration is twofold. The primary objective is to numerically analyze the impact of $\alpha$ and $\beta$ on the optimal order quantity $Q_{0}{ }^{*}$ and the expected profit $E \pi\left(Q_{0}\right)$. The second purpose is to determine the management implications of the models. Even though it is 
TABLE 1

\begin{tabular}{ccccccc}
\hline$\alpha$ & $\beta$ & $Q_{0}{ }^{*}$ & $Q_{a}$ & $Q_{b}$ & $r$ & $E \pi\left(Q_{0}\right)$ \\
\hline \multirow{4}{*}{0.1} & 0.1 & 72.354 & 9.508 & 85.576 & 0.294 & 516.528 \\
& 0.2 & 64.302 & 9.442 & 75.532 & 0.270 & 448.543 \\
& 0.3 & 56.238 & 9.367 & 65.569 & 0.245 & 380.628 \\
& 0.4 & 48.173 & 9.283 & 55.697 & 0.218 & 312.724 \\
& 0.5 & 40.118 & 9.186 & 45.932 & 0.188 & 244.755 \\
& 0.6 & 32.092 & 9.073 & 36.292 & 0.156 & 176.621 \\
& 0.7 & 24.118 & 8.935 & 26.805 & 0.122 & 108.174 \\
& 0.8 & 16.045 & 8.758 & 17.516 & 0.085 & 40.316 \\
& 0.9 & 8.506 & 8.506 & 8.506 & 0.140 & -80.561 \\
\hline
\end{tabular}

TABLE 2

\begin{tabular}{ccccccc}
\hline$\alpha$ & $\beta$ & $Q_{0}{ }^{*}$ & $Q_{a}$ & $Q_{b}$ & $r$ & $E \pi\left(Q_{0}\right)$ \\
\hline & 0.1 & 72.187 & 19.017 & 85.576 & 0.294 & 517.516 \\
& 0.2 & 64.136 & 18.883 & 75.532 & 0.270 & 449.523 \\
& 0.3 & 56.147 & 18.734 & 65.569 & 0.245 & 381.169 \\
& 0.4 & 48.227 & 18.566 & 55.697 & 0.218 & 312.401 \\
0.2 & 0.5 & 40.172 & 18.373 & 45.932 & 0.188 & 244.436 \\
& 0.6 & 32.110 & 18.146 & 36.292 & 0.156 & 176.516 \\
& 0.7 & 24.188 & 17.870 & 26.805 & 0.122 & 103.911 \\
& 0.8 & 17.516 & 17.516 & 17.516 & 0.268 & -61.653 \\
& 0.9 & 7.630 & 7.561 & 17.012 & 0.140 & -82.703 \\
\hline
\end{tabular}

TABLE 3

\begin{tabular}{ccccccc}
\hline$\alpha$ & $\beta$ & $Q_{0}{ }^{*}$ & $Q_{a}$ & $Q_{b}$ & $r$ & $E \pi\left(Q_{0}\right)$ \\
\hline & 0.1 & 72.317 & 28.525 & 85.576 & 0.294 & 516.748 \\
& 0.2 & 64.191 & 28.325 & 75.532 & 0.270 & 449.198 \\
& 0.3 & 56.275 & 28.101 & 65.569 & 0.245 & 380.411 \\
& 0.4 & 48.191 & 27.849 & 55.697 & 0.218 & 312.617 \\
0.3 & 0.5 & 40.118 & 27.559 & 45.932 & 0.188 & 244.607 \\
& 0.6 & 33.368 & 27.219 & 36.292 & 0.156 & 135.444 \\
& 0.7 & 26.805 & 26.805 & 26.805 & 0.385 & -43.170 \\
& 0.8 & 15.658 & 15.327 & 26.274 & 0.268 & -66.316 \\
& 0.9 & 6.676 & 6.616 & 25.518 & 0.140 & -84.865 \\
\hline
\end{tabular}

impossible to derive an optimal solution to both the model without returns and the model with returns, fortunately, it is possible to do so through a numerical illustration. Without losing generality, we assume that the demand follows a normal distribution with mean $\mu=100$ and standard deviation $\sigma=10$. In all numerical tests in this section, the selling price, the penalty cost, the first order purchase cost, the second order purchase cost, the disposal cost, and the return management cost per unit are $p=4, c_{s}=1, c_{p}=3$, $\widetilde{c_{p}}=3.1, c_{d}=1$, and $c_{m}=1$, respectively. MATLAB is used to obtain the closed interval of $Q_{0}{ }^{*}$ and the value of $Q_{0}{ }^{*}$ with a margin of error $\delta=0.01$. We consider different combinations of $\alpha$ and $\beta$, under which the optimal replenishment quantity and the expect profit change correspondingly. Tables 1, 2, 3, $4,5,6,7,8$, and 9 present the optimal procurement quantity and the expected profit when $\alpha$ and $\beta$ change from 0.1 to 0.9 , respectively.
TABLE 4

\begin{tabular}{ccccccc}
\hline$\alpha$ & $\beta$ & $Q_{0}{ }^{*}$ & $Q_{a}$ & $Q_{b}$ & $r$ & $E \pi\left(Q_{0}\right)$ \\
\hline \multirow{4}{*}{0.4} & 0.1 & 72.391 & 38.034 & 85.576 & 0.294 & 516.306 \\
& 0.2 & 64.173 & 37.766 & 75.532 & 0.270 & 449.306 \\
& 0.3 & 56.238 & 37.468 & 65.569 & 0.245 & 380.614 \\
& 0.4 & 48.662 & 37.131 & 55.697 & 0.218 & 303.337 \\
& 0.5 & 42.935 & 36.745 & 45.932 & 0.188 & 155.762 \\
& 0.6 & 36.292 & 36.292 & 36.292 & 0.494 & -25.047 \\
& 0.7 & 23.836 & 22.976 & 35.741 & 0.385 & -50.831 \\
& 0.8 & 13.421 & 13.137 & 35.033 & 0.268 & -71.128 \\
& 0.9 & 5.723 & 5.671 & 34.024 & 0.140 & -87.027 \\
\hline
\end{tabular}

TABLE 5

\begin{tabular}{ccccccc}
\hline$\alpha$ & $\beta$ & $Q_{0}{ }^{*}$ & $Q_{a}$ & $Q_{b}$ & $r$ & $E \pi\left(Q_{0}\right)$ \\
\hline \multirow{4}{*}{0.5} & 0.1 & 72.354 & 47.542 & 85.576 & 0.294 & 516.525 \\
& 0.2 & 64.357 & 47.208 & 75.532 & 0.270 & 446.975 \\
& 0.3 & 57.921 & 46.835 & 65.569 & 0.245 & 343.753 \\
& 0.4 & 52.597 & 46.414 & 55.697 & 0.218 & 174.256 \\
& 0.5 & 45.932 & 45.932 & 45.932 & 0.594 & -7.235 \\
& 0.6 & 32.030 & 30.243 & 45.365 & 0.494 & -36.370 \\
& 0.7 & 19.863 & 19.147 & 44.676 & 0.385 & -59.026 \\
& 0.8 & 11.180 & 10.948 & 43.791 & 0.268 & -75.940 \\
& 0.9 & 4.767 & 4.726 & 42.530 & 0.140 & -89.190 \\
\hline
\end{tabular}

TABLE 6

\begin{tabular}{ccccccc}
\hline$\alpha$ & $\beta$ & $Q_{0}{ }^{*}$ & $Q_{a}$ & $Q_{b}$ & $r$ & $E \pi\left(Q_{0}\right)$ \\
\hline \multirow{4}{*}{0.6} & 0.1 & 73.208 & 57.051 & 85.576 & 0.294 & 502.487 \\
& 0.2 & 67.676 & 56.649 & 75.532 & 0.270 & 374.505 \\
& 0.3 & 62.330 & 56.202 & 65.569 & 0.245 & 192.663 \\
& 0.4 & 55.697 & 55.697 & 55.697 & 0.687 & 10.301 \\
& 0.5 & 40.101 & 36.745 & 55.118 & 0.594 & -23.272 \\
& 0.6 & 25.634 & 24.195 & 54.438 & 0.494 & -49.095 \\
& 0.7 & 15.888 & 15.317 & 53.611 & 0.385 & -67.221 \\
& 0.8 & 8.945 & 8.758 & 52.549 & 0.268 & -80.752 \\
& 0.9 & 3.818 & 3.780 & 51.037 & 0.140 & -91.352 \\
\hline
\end{tabular}

Observations from Tables 1-8 are as follows.

(a) Both $Q_{0}{ }^{*}$ and $E \pi\left(Q_{0}\right)$ decrease as $\beta$ increases.

(b) $E \pi\left(Q_{0}\right)$ is small or negative when $\alpha+\beta \geq 1$, but it is positive when $\alpha+\beta<1$. Namely, when $\alpha+\beta<1$, the expected profit $E \pi\left(Q_{0}\right)$ is always greater than the expected profit under the circumstance of $\alpha+\beta \geq 1$.

\section{Conclusion and Extensions}

In this paper, we present a model for a single period problem with resalable returns and an additional order. Moreover, two kinds of demand, demand for instant delivery and demand for delayed delivery, are considered. The model is resolved with the purpose of maximizing the expected profit. The closed interval of the optimal order quantity is derived, which shows many interesting characteristics. The optimal order 
TABLE 7

\begin{tabular}{ccccccc}
\hline$\alpha$ & $\beta$ & $Q_{0}{ }^{*}$ & $Q_{a}$ & $Q_{b}$ & $r$ & $E \pi\left(Q_{0}\right)$ \\
\hline & 0.1 & 77.516 & 66.559 & 85.576 & 0.294 & 400.373 \\
& 0.2 & 72.194 & 66.091 & 75.532 & 0.270 & 211.836 \\
& 0.3 & 65.569 & 65.569 & 65.569 & 0.773 & 27.590 \\
& 0.4 & 48.096 & 41.773 & 64.980 & 0.687 & -12.321 \\
& 0.5 & 30.089 & 27.559 & 64.304 & 0.594 & -42.452 \\
& 0.6 & 19.226 & 18.146 & 63.511 & 0.494 & -61.822 \\
& 0.7 & 11.918 & 11.488 & 62.546 & 0.385 & -75.416 \\
& 0.8 & 6.712 & 6.569 & 61.307 & 0.268 & -85.564 \\
& 0.9 & 2.861 & 2.835 & 59.543 & 0.140 & -93.514 \\
\hline
\end{tabular}

TABLE 8

\begin{tabular}{ccccccc}
\hline$\alpha$ & $\beta$ & $Q_{0}{ }^{*}$ & $Q_{a}$ & $Q_{b}$ & $r$ & $E \pi\left(Q_{0}\right)$ \\
\hline \multirow{4}{*}{0.8} & 0.1 & 82.104 & 76.068 & 85.576 & 0.294 & 230.786 \\
& 0.2 & 75.532 & 75.532 & 75.532 & 0.854 & 44.654 \\
& 0.3 & 66.703 & 43.712 & 74.936 & 0.773 & -3.333 \\
& 0.4 & 32.087 & 27.849 & 74.263 & 0.687 & -41.543 \\
& 0.5 & 20.061 & 18.373 & 73.491 & 0.594 & -61.635 \\
& 0.6 & 12.817 & 12.097 & 72.584 & 0.494 & -74.548 \\
& 0.7 & 7.951 & 7.659 & 71.481 & 0.385 & -83.610 \\
& 0.8 & 4.473 & 4.379 & 70.065 & 0.268 & -90.376 \\
& 0.9 & 1.908 & 1.890 & 68.049 & 0.140 & -95.676 \\
\hline
\end{tabular}

TABLE 9

\begin{tabular}{ccccccc}
\hline$\alpha$ & $\beta$ & $Q_{0}{ }^{*}$ & $Q_{a}$ & $Q_{b}$ & $r$ & $E \pi\left(Q_{0}\right)$ \\
\hline & 0.1 & 85.576 & 85.576 & 85.576 & 0.929 & 61.513 \\
& 0.2 & 81.309 & 37.766 & 84.974 & 0.854 & 9.206 \\
& 0.3 & 74.972 & 21.856 & 84.303 & 0.773 & -43.749 \\
& 0.4 & 16.040 & 13.924 & 83.546 & 0.687 & -70.771 \\
0.9 & 0.5 & 10.034 & 9.186 & 82.677 & 0.594 & -80.817 \\
& 0.6 & 6.411 & 6.049 & 81.657 & 0.494 & -87.274 \\
& 0.7 & 3.972 & 3.829 & 80.416 & 0.385 & -91.805 \\
& 0.8 & 2.237 & 2.190 & 78.823 & 0.268 & -95.188 \\
& 0.9 & 0.954 & 0.945 & 76.555 & 0.140 & -97.838 \\
\hline
\end{tabular}

quantity is affected by the values of $\alpha$ and $\beta$ mostly, which in turn affect the expected profit of the $\mathrm{B} 2 \mathrm{C}$ retailer.

In order to analyze the impact of the proportion of the immediate delivery needs and the return rate on the optimal order quantity and the expected profit, an approximate method is also used to estimate the changes of the optimal procurement quantity and the corresponding expected profit. Even though it is impossible to derive an optimal solution to both the model without returns and the model with returns, fortunately, it is possible to do so through a numerical illustration.

Through the numerical test, we find that when $\alpha+\beta<1$, the expected profit $E \pi\left(Q_{0}\right)$ is always greater than the expected profit under the circumstance of $\alpha+\beta \geq 1$. In this sense, it is better to keep the sum of $\alpha$ and $\beta$ under 1 so as to profit. If the sum of $\alpha$ and $\beta$ is equal to or more than 1 , the retailer can consider changing the return policy in order to reduce the cost. For instance, the consumers only get partial refund once they return the goods due to their personal reasons. Additionally, the retailer can charge consumers some management fees for the returned products. Furthermore, it is better to keep the return rate under a specific level since the expected profit $E \pi\left(Q_{0}\right)$ increases as the return rate $\beta$ decreases. Provided that the return rate of some products continues to be high, there must be some problem with the product itself. Thus, the retailer can think about pulling them off the shelves. Another interesting finding is that the optimal order quantity $Q_{0}{ }^{*}$ is more affected by the proportion of returns $\beta$ than the ratio of the immediate delivery needs $\alpha$. Therefore, accurately estimating the return rate is important when deciding the first order quantity.

According to the existing research, the expected demand as well as its distribution function undoubtedly influences the order quantity and inventory management [19-21]. On the basis of the newsvendor model, however, instead of the impact of the demand estimation, we mainly focus on the impact of the proportion of the instant delivery needs and the return rate on the order quantity and the expected profit. Following the hypothesis of the newsvendor model, we assume that the demand $x$ for a single product is stochastic, which follows a distribution function $F(x)$ and a probability density function $f(x)$. In the future, we will take the demand forecasting into consideration by using data from the beginning of the sales period.

Further research extensions include freeing the second order quantity as a decision variable. When taking the timing of returns into consideration, we can extend the single period model to a multiperiod problem. For example, returned products arriving after the end of the first selling season can be resold at the next sales period.

\section{Conflict of Interests}

The authors declare that there is no conflict of interests regarding the publication of this paper.

\section{Acknowledgments}

The authors are truly grateful to the lead editor, the guest editors, and anonymous review team. Their comments and suggestions are instrumental in improving this paper. This research is supported by the National Natural Science Foundation of China (Project nos. 71372129 and 71072104) and New Century Excellent Talents (NCET) Program supported by Ministry of Education of China (Project no. 273619).

\section{References}

[1] J. Mostard and R. Teunter, "The newsboy problem with resalable returns: a single period model and case study," European Journal of Operational Research, vol. 169, no. 1, pp. 81-96, 2006.

[2] S. Panagiotidou, G. Nenes, and C. Zikopoulos, "Optimal procurement and sampling decisions under stochastic yield of returns in reverse supply chains," OR Spectrum. Quantitative Approaches in Management, vol. 35, no. 1, pp. 1-32, 2013. 
[3] C. Zikopoulos and G. Tagaras, "Impact of uncertainty in the quality of returns on the profitability of a single-period refurbishing operation," European Journal of Operational Research, vol. 182, no. 1, pp. 205-225, 2007.

[4] M. Ferguson, V. D. Guide Jr., E. Koca, and G. C. Van Souza, “The value of quality grading in remanufacturing," Production and Operations Management, vol. 18, no. 3, pp. 300-314, 2009.

[5] D. Vlachos and R. Dekker, "Return handling options and order quantities for single period products," European Journal of Operational Research, vol. 151, no. 1, pp. 38-52, 2003.

[6] J. Mostard, R. De Koster, and R. Teunter, "The distribution-free newsboy problem with resalable returns," International Journal of Production Economics, vol. 97, no. 3, pp. 329-342, 2005.

[7] J. He, K. S. Chin, J. B. Yang, and D. L. Zhu, "Return policy model of supply chain management for single-period products," Journal of Optimization Theory and Applications, vol. 129, no. 2, pp. 293-308, 2006.

[8] H.-S. Lau and A. H.-L. Lau, "Manufacturer's pricing strategy and return policy for a single-period commodity," European Journal of Operational Research, vol. 116, no. 2, pp. 291-304, 1999.

[9] C. H. Lee, "Coordinated stocking, clearance sales, and return policies for a supply chain," European Journal of Operational Research, vol. 131, no. 3, pp. 491-513, 2001.

[10] S. G. Teng, S. M. Ho, and D. Shumar, "Enhancing supply chain operations through effective classification of warranty returns," The International Journal of Quality and Reliability Management, vol. 22, no. 2, pp. 137-148, 2005.

[11] S. Webster and Z. K. Weng, "A risk-free perishable item returns policy," Manufacturing \& Service Operations Management, vol. 2, no. 1, pp. 100-106, 2000.

[12] C. S. Chung, J. Flynn, R. Kuik, and P. Staliński, "A single-period inventory placement problem for a supply system with the satisficing objective," European Journal of Operational Research, vol. 224, no. 3, pp. 520-529, 2013.

[13] G. Gallego and I. Moon, "Distribution free newsboy problem: review and extensions," The Journal of the Operational Research Society, vol. 44, no. 8, pp. 825-834, 1993.

[14] M. Khouja, "A note on the newsboy problem with an emergency supply option," The Journal of the Operational Research Society, vol. 47, no. 12, pp. 1530-1534, 1996.

[15] H. S. Lau and A. H. L. Lau, "A semi-analytical solution for a newsboy problem with mid-period replenishment," The Journal of the Operational Research Society, vol. 48, no. 12, pp. 1245-1253, 1997.

[16] G. Ferrer, "Yield information and supplier responsiveness in remanufacturing operations," European Journal of Operational Research, vol. 149, no. 3, pp. 540-556, 2003.

[17] A. Robotis, S. Bhattacharya, and L. N. Van Wassenhove, "The effect of remanufacturing on procurement decisions for resellers in secondary markets," European Journal of Operational Research, vol. 163, no. 3, pp. 688-705, 2005.

[18] M. Kodama, "Probabilistic single period inventory model with partial returns and additional orders," Computers \& Industrial Engineering, vol. 29, no. 1-4, pp. 455-459, 1995.

[19] M. A. de Bodt and S. C. Graves, "Continuous-review policies for a multi-echelon inventory problem with stochastic demand," Management Science, vol. 31, no. 10, pp. 1286-1299, 1985.

[20] J. C. Ehrenthal, D. Honhon, and T. Van Woensel, "Demand seasonality in retail inventory management," European Journal of Operational Research, vol. 238, no. 2, pp. 527-539, 2014.
[21] T. L. Urban, "Inventory models with inventory-level-dependent demand: a comprehensive review and unifying theory," European Journal of Operational Research, vol. 162, no. 3, pp. 792804, 2005. 


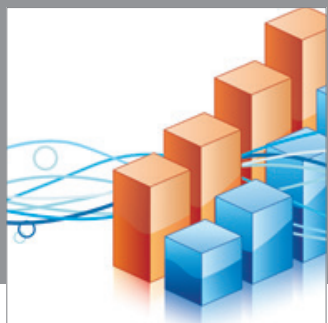

Advances in

Operations Research

mansans

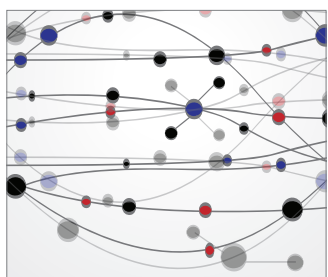

The Scientific World Journal
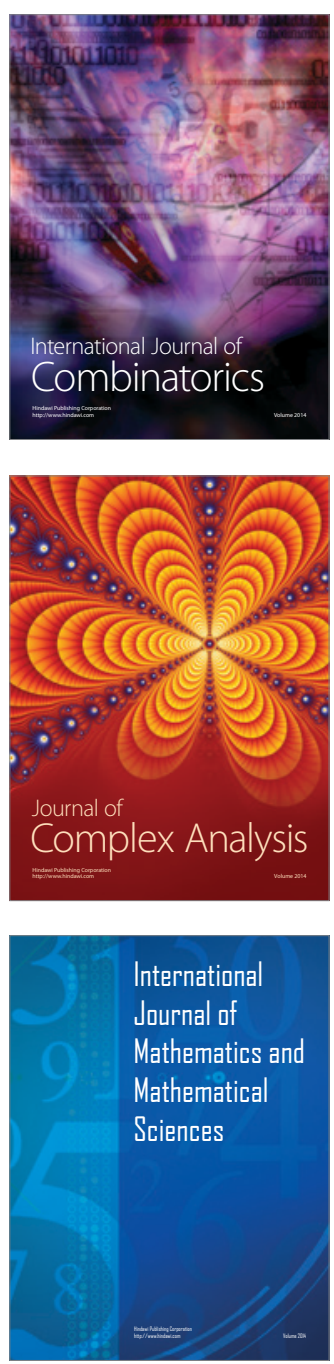
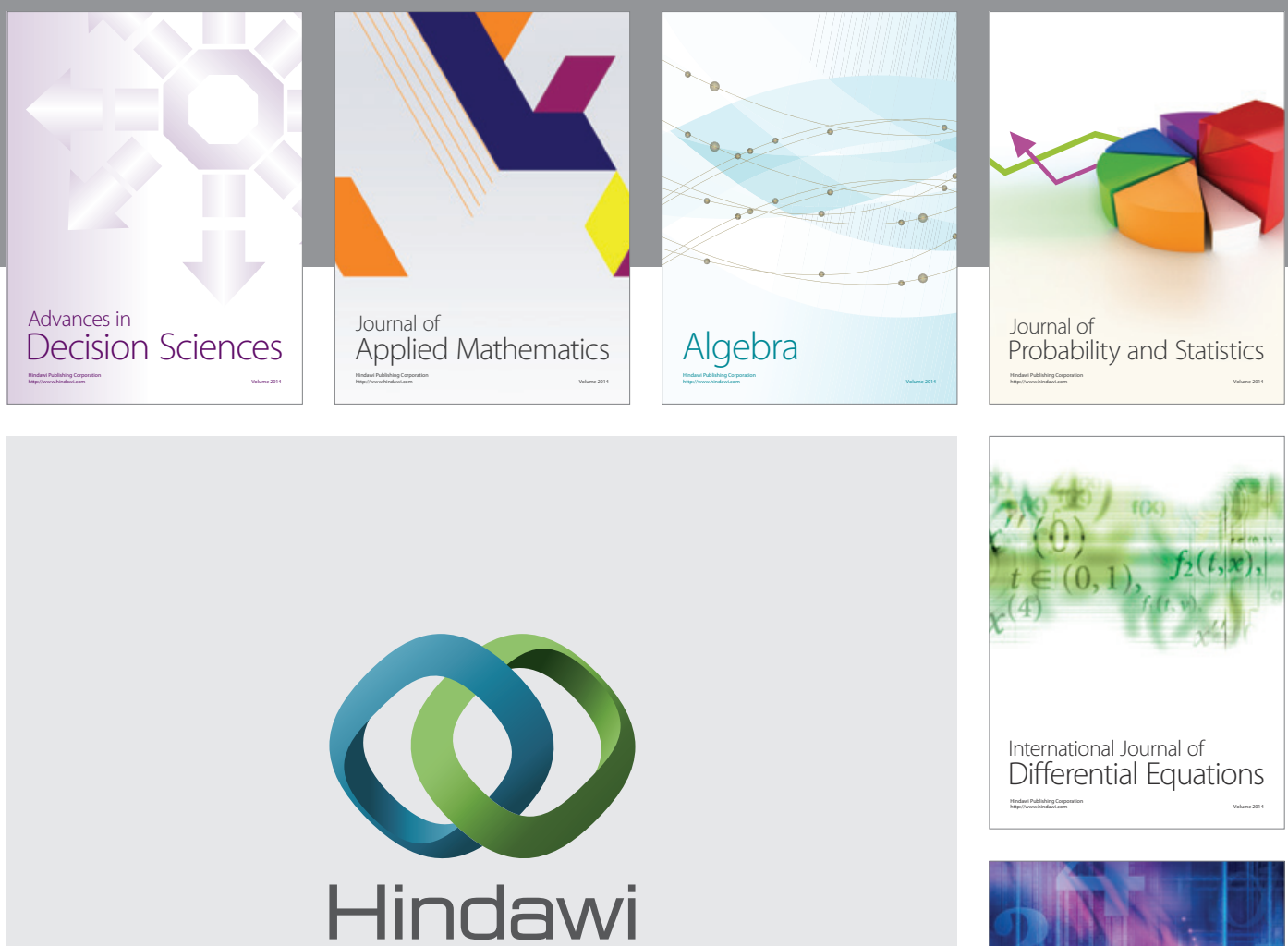

Submit your manuscripts at http://www.hindawi.com
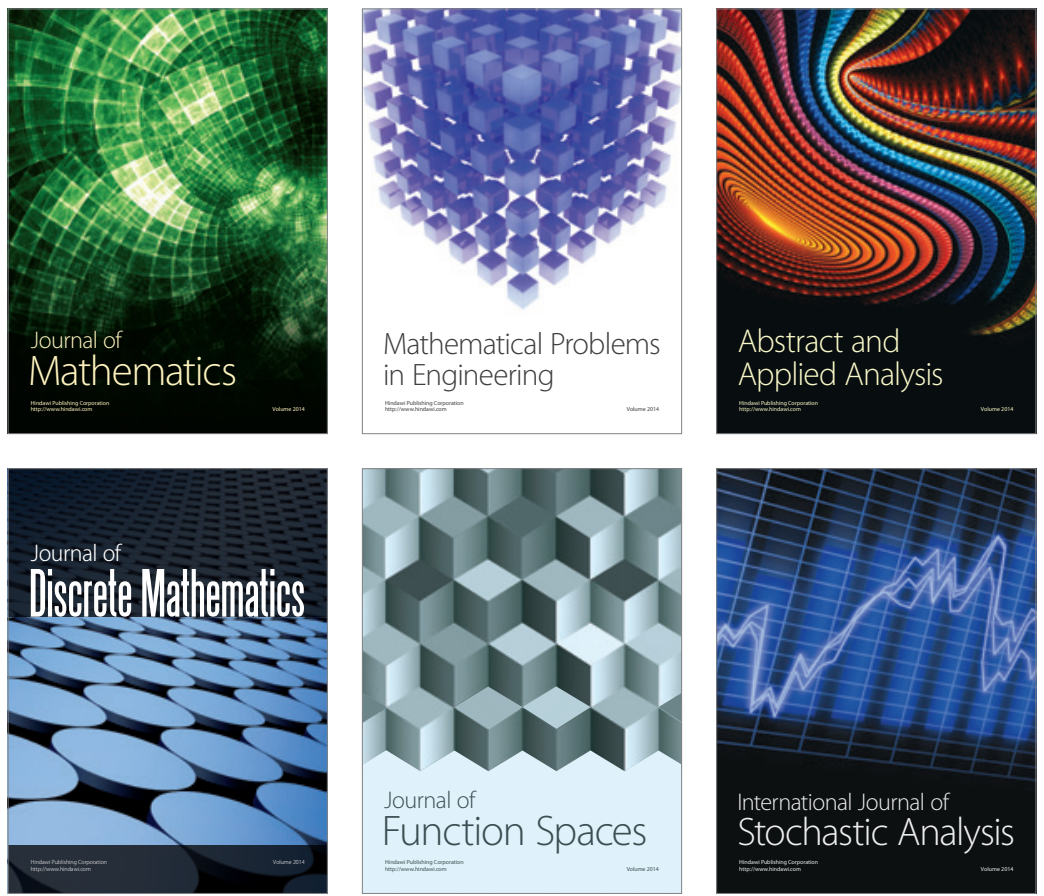

Journal of

Function Spaces

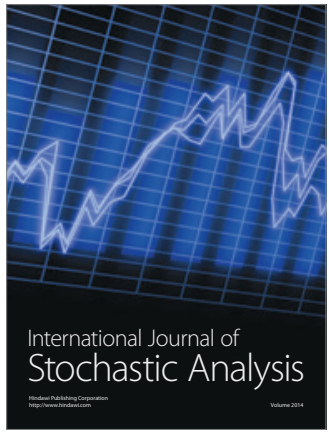

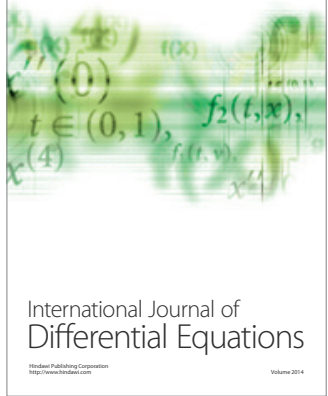
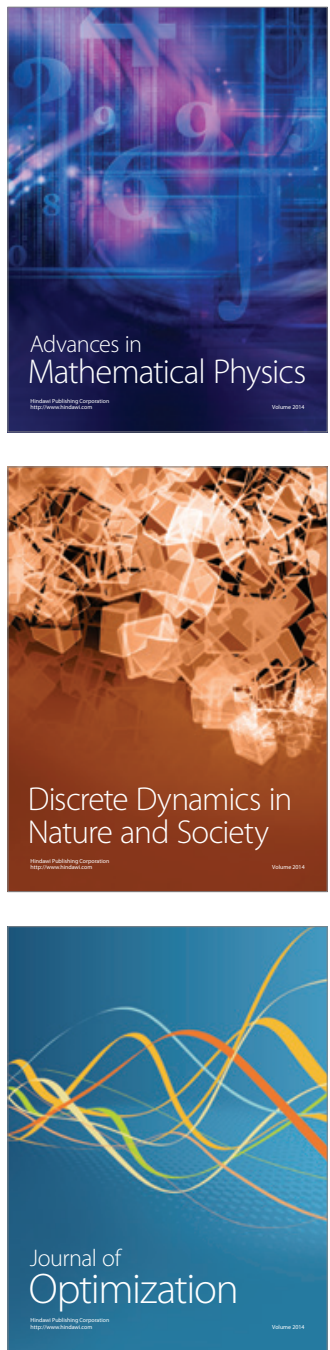